brothers and sisters have, from a contrary cause, all died; or have originally come out as phthisical, and have lived freo from all tubercular complaint.

Anguet 1859.

\section{TWO FATAL CASES OF SNAKE-BITE: WITH REMARKS.}

By R. H. POWELL, M.D.Lond.

(Read before the Harveian Society of London.)

Case I. The following particulars of a case of snake-bite were furnished by A. MacKean, Esq., late in medical charge of Mhairwara Local Battalion.

The accident occurred to a Sepoy, who was, I think (says the reporter), in the district on command; and when he was brought in, of course there was nothing to be done but to give spirits of ammonia from time to time. No particular symptoms supervened, if I except a disposition to drowsiness, and latterly acute inflammation of both conjunctivæ, for which leeches were applied to the under eyelids, and cooling purgatives administered. After the leeches had been applied, it became apparent that the leech-bites continued to bleed, and neither dossils of lint, applications of turpentine, nor of lunar caustic could command the partial bleeding from them. After the case had been altogether some three or four days in hospital, the man gradually fell into a lethargic state, from which he never could be roused. His leg was somewhat swollen on admission to hospital; and as no very urgent symptoms showed themselves, I was in hopes the case would have done well; but in this I was disappointed. It is impossible for me to say what kind of snake bit the man ; nor can I positively assert it was a snake that bit him, but in all likelikood it was a case of snake-bite.

There are no further particulars to communicate. (Signed)

N. Colsrer, Assistant Surgeon, Mhairwara Local Battalion.

February 3rd, $18+1$.

The second case is reported by Mr. Davidson, surgeon, -th Light Infantry.

Case II. Lieut. C. A., -th Light Cavalry, aged about thirty-three years, was bitten by a snake on the left instep, through a thin cotton stocking, on the night of the 11 th June 1840, between nine and ten o'clock, when walking home from the regimental mess-house, and was brought to me about twenty minutes after the accident. Immediately on his being bitten, a ligature was tied tightly round the leg, and in a few minutes after a large dose of eau-de-luce (about 3 iiss), was given. On arriving at my house, he had no particular symptoms of the effect of the poison. He was anxious; the pulse was soft; he complained of soreness of his throat from the eau-de-luce. He had slight pain in the part which was bitten, the punctures were very distinct, and had a black appearance, and the foot was very slightly swollen. The part was cut out with a scalpel ;* it consisted of the common integuments and cellular substance, to the extent of about nine lines in length, and eight in breadth, over the os naviculare, and on the inner side of the extensor proprius pollicis pedis. It was allowed to bleed a little; and was then touched with lunar caustic, and a poultice was applied.

About two hours after the bitten part was cut out, he became restless, giddy, and sick, with a strong inclination to go to stool, and bleeding took place from the wound. On removing the poultice, the blood was found oozing out as from a sponge; and pressure having no effect in stopping it, though no vessel of any size was cut, or could be seen, ligatures were applied at every place where any distinct point could be discovered, and then a compress and bandage were applied. In spite of this, however, the bleeding continued, and the actual cautery was had recourse to, and a firm com-

- A curved instrument, somewhat like a tenaculum, has been lately recommended for cauterising the punctures; following up their track, and effectually destroying the bitten tissue. press and bendage put on. Two doses of en-de-luce, the first of $3 j$, and the second of forty minims, were given bJ me; and afterwards, from the pain in the throat, liquar ammonio in forty minim doses, and then compound spirit of ammonis in drachm doses, in camphor-mixture, repeated at longar or shorter intervals, from half an hour to an hour. As the pulse became weak and slow, and as no further symptoms of the effect of the poison continued, except the oozing of blood from the wound, early on the morning of the 12th, the ammonia was discontinued. As the bleeding from the wound, though much diminished after the application of the cautery, did not stop entirely, he, on the afternoon of the 12th, commenced taking subacetate of lead, in three grain doses, with half a grain of opium, every three hours, and this was continued regularly up to the morning of the 15th.

On the forenoon of the second day (the 13th), the foot and leg were swelled and painful to the touch, but cool. The part had a blueish appearance, and several purple blotches were observed on different parts of the body, particularly on the left arm; which spots afterwards became larger and of a darker colour. His bowels were acted on by pilul. colocynth. c. aloes grs. viij, with pilul. hydrarg. gr. ij, at bed time, followed by an enema the next day when nocessary, and his strength was supported. Excepting a slight oozing of a light-coloured watery blood from the wound, he appeared to be getting on well till the afternoon of the $15 \mathrm{th}$, the fourth day after the bite. His pulse then increased in strength and frequency; he complained of headache, sickness, and loss of appetite; and became much heated, with swelling, heat, and pain of the foot and leg, nearly up to the knee. Cold lotion was applied to the foot and leg, and eight grains of extract of colocynth, with the same quantity of calomel, were given; and the bowels not having boen acted on in three hours, a solution of three drachms of Fpsom salts, in two ounces of water, was given every two hours. After the third dose of this, as his bowels had not been acted on, a purgative enema was given, which operated freely. After his bowels were opened, he began to take a draught consisting of

Liquor. acetat. ammoniæ] 3 ij.

Vini antimon. tartarizat. me. $\mathrm{xx}$.

Mist. camph. Z zj.,

every second hour. Under the use of this the febrile symptoms subsided. During the night he was restless, and suffered a good deal from sickness, which was relieved by efferrescing draughts.

Early on the morning of the 16th, he complained only of great weakness. Suddenly, in the foremoon, a little before twelve o'clock, a profuse damp perspiration broke out all over his body, followed immediately by convulsions. He was after this unable to speak. Slight convulsive twitchings of the extremities continued, and he gradually sank and died at a quarter past two P.M., of the 16th.*

Examination of THE BODY three and a half hours after death. Externally nothing particular was observable, with the exception of the blotches on the different parts of the body, which had, from an inky blue colour, become brownish; and the discoloured state of the left leg, which had a blueish tinge extending up nearly to the knee. On examining the wound, a thin slough appeared to be separating, and there was a slight formation of matter round its edges, but no arterial branches could be traced into it. On cutting into the parts, there was slight extravasation of blood in the cellular substance around the wound.

Abdomers. The viscera were generally healthy; but the liver was rather large, particularly the right lobe, on the convex surface of which there was a mark of an old cicatrix, about two and a half inches long, and there was a red patch on its surface near to this place.

- It may be surmised that the treatment pursued subsequently to the exbibition of depressing astriugents proved too active for a system labouring under the sedative infinence of a virulent poison. The latter part of the treatment was, however, judicious; and in such cases little room is laft tor oritical remarks, from their all but unirergel fatality. B. II. P. 
Thorax. The chest appeared rather small. There were chronic adhesions of both lungs, which were otherwise healthy. The pericardium was thin, and contained about two ounces of a pale-coloured fluid. The heart was very large, but not apparently changed in structure. The blood in the heart, as also in all the large vessels, both arteries and veins, of the thorax and abdomen, was quite fluid; and no coagulum of blood was found in any part of the body: its colour was also very light, and its consistence watery.

Head. The membranes and substance of the brain showed no diseased appearance. The lateral ventricles contained a small quantity of fluid, and the choroid plexus was of a rather pale colour. The cercbellum was soft. There was a considerable quantity of fluid in the spinal canal. The blood here, as in all other parts of the body, was of a light colour and very thin.

Remanks upon this case by the reporter. The patient remained in my house. Mr. Griffiths, surgeon, 74th Regiment, N.I., saw him carly on the morning of the 12th at my request, and continued to attend upon him with me till death occurred, and was present at the examination of the body. In this case the active effects of the poison were counteracted, to a certain extent, by the large dose of eau de Zuce; but the system was much affected by the virus, as was evident from the change produced upon the blood, the oozing of it from the wound, and the blotches on different parts of the body. Death was caused from the poison acting so severely upon a constitution which was much weakened by former illnesses. The snake was seen by Lieut. A., as well as by servants who were with him; and, though it was not killed, I have no doubt that the bite was inflicted by the harait, a most venomous snake, which is common at this place. The effect of its bite is to produce a great change upon the blood, and to cause discharges of it to take place from the wounds inflicted by the animal-whether the parts be cut out or scarified or not, ${ }^{*}$ as also from other parts of the body, as from the nose, or mouth.

Lieut. $\Lambda$. was of a spare habit of body, middle size, dark complexion, and of regular but rather sedentary habits. When coming out on board of ship, he had a fall on his back, which injured his spine so severely, that for some months after his arrival he was unable to do his duty. He did duty with the cavalry for a few months in the cold season of 1828, and was afterwards posted to it and joined in December 182.9. During the time he was with the regiment, in 1830 and 1831, he was more or less an invalid. suffering from affections of the liver, and obstinate constipation, for which (besides other means) he was obliged daily to have recourse to purgatives and enemata. On the march of the regiment, in January and Fcbruary 1832, he was attacked with fever, from which he suffered severely, and afterwards was so reduced and debilitated, that in this year he was sent on sick leave to England, but was a long time before he derived benefit from the change of climate, and for a considerable period he was obliged almost constantly to have recourse to the use of purgatives. In April 1837 he joined his corps on his return from England, and continued pretty well for some time afterwards. In 1838 and 1839, he was three times on the sick list, for considerable periods, for the treatment of primary and secondary symptoms, for which it was absolutely necessary to put him through protracted courses of mercury (it being difficult to bring his system under the influence of it); sarsaparilla and nitric acid being afterwards given. In December 1839 he got his right ankle hurt by falling over a tent-pin. Inflammation took place, for which leeches were applied; but the wounds ulcerated, and did not heal up for nearly a month. In April and May, he suffered from chronic disease of theliver; when blistering, counter-irritation, and mercurial alteratives and purgatives were given, with the effect of re-

Why excise the bitten part in this case, if the absorption of the virus be not thereby arrested? It is probsbly a question iuvolving the time and mode of perforning the oporation; speed and dexterity, with the subsequent use of additional means likely to still further promole the object in view, use of auditional means likely to still furth
being the requites for success. R. H. P. moving the symptoms. With the exception of suffering from gonorrhoes, he continued pretty well after this up to the time of being bitten by the snake.

$$
\text { (Signed) }
$$

Alex. Davidsor, Surgeon Light Cavalry.

It may be doubted whether, in the above case, the lead and opium acted beneficially; as, while they moderated tho discharge of blood from the wound, secretion and excretion were probably checked, and the eliminating process usually set up by the glandular apparatus was arrested in its salutary operation of freeing the blood and system from deleterious agents : the supervention of low congestive disorder being also proportionally facilitated.

General Remarks upon Snake-Poisoning. With regard to the nature of the snake virus, it would appear to be related to those bodies, occasionally present in the blood as the result of or in connexion with defective excretion, and which, though differing greatly in des ree of virulence from the former, exert an injurious influence not very dissimilar in kind.

The mode of operation of the snake virus on the blood, seems to consist of and originate in a catalytic influence, whereby the essential propertics of the blood becoming altered, its constituent parts are broken up, and fall into lower and more simple organic combinations. These changes probably take place in those composite bodies formed by the mineral and azotised constituents of the blood conjointly. It would appenr, from the foregoing and similar cases, that the fibrin and red globules are especially attacked and modified, as by other noxious agents; the plasticity of the blood being diminished and its fluidity increased, as in death from lightning, and from diseases in which those ingredients. are affected. The cachectic state of the patient in the second case, related above, still further promoted the baneful operation of the snake-poison, in spite of the treatment occasionally found uscful in this form of toxamia. It is worthy of remark, however, that the antidote (ammonia) to those subtile and rapidly acting poisons, contains nitrogen; and that when promptly exhibited, it may be concluded to bear the early impression and attack of the snake venom rapidly gaining access to the circulation, and there neutralising its lethal activity, and thus preventing the decomposition above referred to.

It is obvious that, if the blood become chemically altered, congestion and other secondary disturbances of function may readily ensue, and make up the train of symptoms characterising such cases. There appears to be some analogy between the poisonous action of the snake secretion and that of belladonna; both producing tumefaction of the throat and of the eyelids, affection of the pupils; cerebral congestion, etc., supervening. Further, the excretion from the kidneys of uric acid and non-combustible salts is diminished by the latter agent, thereby permitting the accumulation in the blood of those injurious compounds previously mentioned. The alleged prophylactic power of belladonna in scarlatina, in which the presence of a zymotic agent may be assumed, may be derived from the incompatibility of two concurrent morbid operations in the economy, or to the fact of one catalytic agent, as it were, using up the pabulum required in the evolution of the other.

Moreover, Dr. Prout signalised the peculiar state of combination in which sulphur, iron, phosphorus, etc., are found in the organic principles of the blood. It may be in virtue of the poisonous ferment breaking up this combination that we are, in part at least, to attribute the formidable change of properties, and ultimate dissolution of the blood; either directly, by the formation of some less highly complex bodies; or indirectly, by the subtraction of the influence exerted by those elements in conserving the organised bases of the tissues from the operation of extra-organic chemical affinities.

Edward Street, Portman Square, August 1853. 